\title{
H.A. Tuк
}

\section{РОМАН А.С. ПУШКИНА «ЕВГЕНИЙ ОНЕГИН» В ПЕРЕВОДАХ Э. ЛО ГАТТО}

\begin{abstract}
Работа посвящена переводческой рецепции романа А.С. Пушкина «Евгений Онегин» итальянского слависта Этторе Ло Гатто. Объектами внимания исследования являются: эволюция переводческой стратегии Э. Ло Гатто, проблема выбора формы для перевода «романа в стихах», трансформация композиционной структуры оригинала и возможности передачи смыслопорождающего потенциала пушкинского текста в прозаическом и поэтическом вариантах перевода Ло Гатто.

Ключевые слова: Этторе Ло Гатто; Евгений Онегин; художественный перевод; пушкиноведение; русско-европейские литературные связи.
\end{abstract}

Актуальность настоящего исследования обусловлена непрекращающимся интересом современной гуманитарной науки к диалогу культур, проблемам рецептивной эстетики и переводоведения. В контексте большого количества работ отечественного и зарубежного литературоведения, посвященных западноевропейской рецепции романа А.С. Пушкина «Евгений Онегин» (особенно английской, немецкой, французской), история рецепции романа в Италии исследована в меньшей степени. В связи с чем представляется актуальным изучить итальянскую рецептивную историю «Евгения Онегина», дополнив тем самым общую картину восприятия и функционирования романа в стихах в западноевропейском и мировом культурном пространстве.

В настоящее время существует десять полных переводов романа А.С. Пушкина «Евгений Онегин» на итальянский язык, предпринятых с 1856 по 2006 г. ${ }^{1}$ Среди них особое место занимают два перевода, прозаический и поэтический, выполненные одним автором - итальянским славистом Этторе Ло Гатто. Роль переводов и литературоведческих трудов Э. Ло Гатто в формировании представления о России и русской литературе у итальянского читателя сложно переоценить: Ло Гатто - переводчик, исследователь русской литературы и культуры, а также русско-итальянских взаимосвязей, главное действующее лицо «в ситуации, которую позже назвали рождением итальянской “русистики"» [1. С. 7 $]^{2}$.

Предлагаемая статья посвящена переводческой рецепции Э. Ло Гатто романа А.С. Пушкина «Евгений Онегин». Основные задачи: проследить эволюцию переводческой стратегии Э. Ло Гатто, исследовать причины выбора формы для перевода «романа в стихах», особенности композиционной организации и возможности передачи ассоциативного и смыслопорождающего потенциала пушкинского текста в прозаическом и поэтическом вариантах перевода.

Выбор Ло Гатто прозаической формы для первого перевода «Евгения Онегина» (1923), по его собственному признанию, был обусловлен знакомством с переводом Дж. Кассоне (1906), не вызвавшем у Ло Гатто желания повторить подобный «поэтический» переводческий опыт: «...знакомство с переводом Кассоне, выполненным нерифмованным одиннадцатисложником, утвердило меня во мнении $<\ldots>$ о сложности или даже невозможности передать итальянскими стихами иностранную поэзию, в особенности стихи такого поэта, как Пушкин» ${ }^{3}$ [2. С. 208-209] (здесь и далее перевод мой. - H.T.). Но несмотря на это утверждение (а также на то, что перевод стихов прозой - явление вполне традиционное для итальянской переводческой практики тех лет), исследователя продолжает занимать мысль о поиске возможности перевести «роман в стихах» стихами, и он вновь обращается к пушкинскому тексту. Мотивы, побудившие его приступить к работе над стихотворным переводом, Ло Гатто не раз называет в своих письмах и литературоведческих статьях: «Работа эта была задумана давно: речь шла о том, чтобы преодолеть в себе изначальное неприятие стихотворного перевода. Короче: я начал полусерьезно-полушутя переводить пушкинского «Онегина», которого, $<\ldots>$ более десяти лет тому назад перевел в прозе» [1. С. 48]; «Мне хотелось победить собственное отвращение к стихотворному переводу вообще, победить собственным стихотворным переводом» [3. C. 761]; «чтение и перечитывание "романа в стихах" побудило меня предать самого себя. Учитывая, что русский поэт, в сущности, в определенном смысле сам отрицал, что его “роман” может быть переведен прозой $<\ldots>$ в чем и заключался смысл его заявления: “роман в стихах, дьявольская разница", мое решение было неким вызовом самому себе» ${ }^{4}$ [2. С. 209].

Последняя цитата ассоциативно корреспондирует c известной итальянской поговоркой «traduttore, traditore» («переводчик - предатель»), смысл которой в том, что перевод может искажать текст и авторский замысел оригинала. Ло Гатто же ставит вопрос о предательстве переводом не автора оригинала, а самого переводчика, что также верно: переводчик зачастую находится под воздействием собственной национальной литературной традиции (например, неприятие Ло Гатто «стихотворного перевода вообще» - это следствие влияния на него итальянской традиции перевода стихов прозой), и преодоление силы воздействия этой традиции действительно, до некоторой степени, является предательством «самого себя».

Ло Гатто удается осуществить его «дерзкий замысел» [1. С. 48], и в 1937 г. исследователь знакомит итальянского читателя с плодом «настоящей одержимости и многих ночей без сна» [Там же] - со своим новым переводом, на этот раз стихотворным. Для перевода пушкинского 4-стопного ямба Ло Гатто выбирает одиннадцатисложник, называя при этом свой выбор инстинктивным: «При выборе одиннадцатисложника мною руководил в большей степени ин- 
стинкт, нежели рассудок» ${ }^{5}$ [2. С. 211]. Но помимо отправного «инстинктивного» движения, у Ло Гатто была по крайней мере еще одна причина для выбора одиннадцатисложника: уже во время своей работы над прозаическим переводом он замечает явное сходство онегинской строфы с итальянским сонетом, законы жанра которого требуют определенного размера и рифмы (а также особой схемы рифмовки, которой Ло Гатто, однако, не придерживается, сохраняя схему рифмовки онегинской строфы - оригинального пушкинского изобретения). Национальная поэтическая традиция в каждом языке закрепляет за определенными размерами присущие лишь им функции, на которые и следует ориентироваться переводчику: «...для создания интонации оригинала в поэтическом переводе нужно найти размер, соответствующий выразительным ритмико-интонационным средствам оригинала, и совсем не обязательно повторять размер подлинника $<\ldots>$ таким образом, стих одного языка передается наиболее близким по характеру стихом другого языка, а не прямым перенесением метрическом схемы» [4. С. 93]; «Важно находить такие соответствия, которые основывались бы <..> на сходстве устоявшихся в употреблении того или иного размера в двух метрических системах» [5. С. 71-72] - и таким «соответствием» русскому 4-стопному ямбу в итальянском языке является именно одиннадцатисложник 6 . Дополнительным подтверждением «правомерности» выбора Ло Гатто одиннадцатисложника может служить отзыв о его переводе Вячеслава Иванова, русского поэта, в совершенстве владевшего итальянским языком: «Не хватало до сих пор не только верного, но и художественного итальянского и, - что существенно, - исполненного в чисто итальянских рифмах, перевода» [7. С. 653].

При анализе прозаического и поэтического вариантов перевода Ло Гатто представляется целесообразным рассматривать переводной текст с точки зрения тех свойств и особенностей, которые являются принципиальными для жанровой специфики оригинала (как лироэпического целого). Не имея возможности в рамках данной работы подробно остановиться на реализации всей совокупности жанровых признаков «романа в стихах» в переводах, ограничимся двумя проблемами: воссоздание композиционной структуры и передача ассоциативного и смыслопорождающего потенциала оригинального текста. Известно, что композиционный замысел Пушкина менялся в процессе работы над текстом (и до сих пор вопросы о намеренном или вынужденном изменении композиционной структуры, статусе «Отрывков из путешествия Онегина» и т.п. являются предметом споров даже отечественных литературоведов), кроме того, роман существует в двух редакциях (поглавная и полная), поэтому представляется необходимым проследить, какой редакции придерживается Ло Гатто, а также воспроизводит ли он соотношение поэтических и прозаических компонентов текста. Что касается воссоздания переводчиком ассоциативного и смыслопорождающего потенциала оригинала, данная проблема представляется актуальной в связи с тем, что возможность генерировать смыслы и ассоциации при сравнительно небольшом объеме - это ведущее свойство «Евгения Онегина» как стихотворного текста. В данном случае нас будут интересовать следующие элементы текста, участвующие в организации романа в стихах как единого целого и обладающие смыслопорождающим потенциалом: тематический повтор и игра с читателем, его вовлечение в акт творения романа.

Пушкинский роман (полная редакция) композиционно организован следующим образом: прозаический эпиграф на французском языке; стихотворный эпиграф-посвящение; 8 глав в стихах; примечания Пушкина; отрывки из путешествия Онегина.

Композиция прозаического перевода Э. Ло Гатто содержит:

- Предисловие «Александр Пушкин и “Онегин”» (Introduzione «Alessandro Puškine L' “Onjéghin”»);

- посвящение Л.С. Пушкину к первому изданию первой главы (Dedica della prima edizione del primo capitolo: Dedicato a mio fratello Leone Serghjeevič Puškin);

- предисловие к первому изданию первой главы: «Вот начало большого стихотворения...» (Prefazione alla prima edizione del primo capitolo);

- посвящение П.А. Плетневу (А Pietro Aleksandrovič Pletnjòv);

- прозаический эпиграф на французском;

- 8 глав в прозаическом переводе;

- приложения к «Онегину» (Appendici all' «EugenioOnjéghin»): «Странствия Онегина» (Le peregrinazioni di Onjéghin), «Альбом Онегина» (L’Album di Onjéghin), «Дополнительные строфы» (Strofe supplementari), «Попытки возвращения к «Евгению Онегину» ${ }^{7}$ (Tentativi di ritorno ad «Eugenio Onjéghin»);

- примечания Пушкина (к изданиям отдельных глав и к полному изданию 1833 г.);

- заметки переводчика.

При жизни А.С. Пушкина роман целиком был напечатан дважды $(1833,1837)$ в редакции, установленной самим поэтом, что дает основания считать текст дефинитивным. Однако в прозаическом переводе Ло Гатто на уровне композиционной организации можно наблюдать ряд несовпадений с окончательной пушкинской редакцией: перенос композиционных частей и включение в текст фрагментов из ранних и черновых редакций романа. Необходимо отметить, что все эти фрагменты специально обозначаются в тексте как дополнительные, а также получают освещение в «Заметках переводчика», в которых Ло Гатто подробно комментирует пушкинский текст: отдельные строфы, строки, слова; дает культурологический и лингвистический комментарий реалиям («“присядка" в русском национальном танце обозначает набор движений, который включает в себя: приседание, резкое выбрасывание ног вперед и быстрый подъем» ${ }^{8}$ [8. Р. 258]; «Мы обычно говорим “il Volga". Представляется необходимым оставить названию женский род, учитывая значение, которое для русских имеет выражение "Волга-матушка"9 [Ibid. P. 268]); объясняет итальянскому читателю имена исторических персонажей (Iaroslav «Il Savio», Stenka Razin), аллюзии на персонажей литературных произведений (Childe- 
Harold, Ciatskij) и реальных друзей и знакомых Пушкина (Vjazemskij, principessa M. Volkonskaja), упоминает о книгах из библиотеки поэта, обстоятельствах его дуэли с Дантесом, цитирует письма Пушкина, работы советских пушкинистов и пр.

Такой подробный корпус комментариев и вставки в перевод текстов, относящихся к творческой истории романа, обнаруживают ориентацию переводчика на неподготовленную аудиторию, желание все объять и объяснить, донести «всего Пушкина» до итальянского читателя.

Композиция поэтического перевода Э. Ло Гатто выстраивается следующим образом:

- двухчастное предисловие (первая часть Вяч. Иванов о переводе Ло Гатто, вторая - Ло Гатто о жизни и творчестве Пушкина);

- примечание, касающееся перевода русских имен и композиционной организации перевода (Avvertenza);

- прозаический эпиграф на французском;

- стихотворный эпиграф-посвящение;

- 8 глав в стихотворном переводе. Каждой из глав предшествует прозаический комментарий, в котором Ло Гатто знакомит читателя с названиями глав, данными Пушкином в его «Плане» 1830 г. («Хандра», «Поэт» и пр.), дает краткую информацию об обстоятельствах, при которых глава была написана и впервые опубликована, сообщает краткое содержание главы;

- примечания Пушкина;

- отрывки из путешествия Онегина (также предваряющиеся прозаическим комментарием Ло Гатто);

- заметки переводчика (Nota del traduttore);

- пояснительные замечания (Note esplicative): краткий комментарий переводчика к отдельным строфам каждой главы романа.

В стихотворном переводе отступлением от оригинальной композиционной структуры является включение комментариев переводчика непосредственно в текст романа. Данные комментарии отличаются от комментариев, вынесенных за текст. Во-первых, в них отсутствует указание на принадлежность текста переводчику (ср.: во всех переводческих «заметках» и «замечаниях» присутствует соответствующее заглавие («Nota del traduttore», «Note esplicative»), а также подпись переводчика, полное имя или инициалы (Ettore Lo Gatto, e.l.g). Кроме того, об этих комментариях не упоминается в примечании («Avvertenza»), в котором Ло Гатто дает пояснения относительно других своих комментариев к тексту («Nota del Traduttore», «Note esplicative»). Предваряя каждую из восьми глав (следуя за эпиграфами), а также «Отрывки из путешествий Онегина», комментарии переводчика могут давать повод для восприятия их в качестве прозаических элементов оригинального текста (подобно пушкинским прозаическим предисловиям и примечаниям). Упоминание автора-Пушкина (романного или реального) в некоторых комментариях не дают оснований однозначно атрибутировать их Э. Ло Гатто, поскольку Пушкин в романе неоднократно говорит о его авторе в третьем лице, ср.:

Э. Ло Гатто: «Ricco di digressioni e di riferimenti autobiografici, il capitolo si chiude con le amare previsioni dell'autore sull'accoglienza che la sua opera avrà dalla critica» [9. P. 22].
Подстрочный перевод: «Изобилующая отступлениями и автобиографическими отсылками, глава завершается горькими прогнозами автора относительно будущего приема его романа критикой» (Здесь и далее перевод мой. - H.T.).

А.С. Пушкин: «<..> Скромный автор наш перевел только первую половину славного стиха» [10. С. 193].

Э. Ло Гатто: «<...> nel piano retrospettivo del «romanzo» fatto da Puškin <...>» [9. C. 22].

Подстрочный перевод: «<..> в ретроспективном плане “романа", созданном Пушкиным <..>».

А. С. Пушкин: «А.П.», «Сам П. говаривал» ${ }^{10}[10$. C. 529].

Во-вторых, в комментариях прослеживается связь с ранними редакциями романа, ср.:

Э. Ло Гатто: «In esso il protagonista viene presentato come un giovane esponente della nobiltà pietroburghese, imbevuto di byronismo ed irrimediabilmente annoiato della vita di società che conduce» [9. P. 22].

Подстрочный перевод: «В ней главный герой молодой представитель петербургского света, проникнутый духом байронизма и безнадежно утомленный светской жизнью, которую он ведет».

Первое отдельное издание 1-й главы (1825): «Первая глава представляет нечто целое. Она в себе заключает описание светской жизни петербургского молодого человека в конце 1819 года и напоминает Беппо, шуточное произведение мрачного Байрона» [10. C. 638].

Если в прозаическом переводе Ло Гатто специально композиционно выделяет тексты, не вошедшие в полную редакцию «Евгения Онегина», то в стихотворном переводе фрагменты этих текстов оказываются включенными в переводческий комментарий, сам комментарий при этом оказывается внутри переводного текста романа - происходит сращивание перевода и комментария, что дает основание для постановки проблемы восприятия границ дефинитивного художественного текста переводчиком. Обращение Ло Гатто к ранним редакциям, черновым вариантам романа, введение их в переводной текст, а также стремление текст прокомментировать обнаруживают интенцию переводчика как можно более полно и точно донести до итальянского читателя, аудитории совершенно неподготовленной, смысл пушкинского романа (примета филологического перевода), а также свидетельствует о том, что, перевод «Евгения Онегина» для Ло Гатто - не просто перевод художественного текста иноязычного автора, но создание пространства особого духовного взаимодействия с пушкинским текстом и самим Пушкиным. Стремление к комментарию - традиционный пушкинский прием, и, пользуясь им, внедряя в текст комментарий, Ло Гатто, с одной стороны, демонстрирует инстинктивное «чувствование» пушкинского романа, но с другой - инстинктивное недоверие к самостоятельной коммуникативной и информативной достаточности стихотворного текста.

Стихотворная речь обладает таким смыслопорождающим потенциалом, который превышают сумму семантики участвующих в этом процессе элементов. И чтобы воссоздавать образно-смысловые оттенки 
при переводе, не обязательно воспроизводить данные элементы буквально, можно, а зачастую даже необходимо, заменять их другими, исходя из возможностей переводящего языка. Традиционно выделяют три вида специфично стиховых структур: метрико-ритмические, фонические (звукобуквенные), металогические (словесно-образные), которые, «действуя совокупно, осуществляют многомерную интеграцию словесного материала, «перерабатывают» фактуальный смысл в концептуальную и эстетическую информацию» [11. С. 107].

Обратимся к означенным структурам и рассмотрим, как они реализуются в стихотворном переводе Ло Гатто (для сравнения привлечем также прозаический перевод) на двух примерах:

1. А.С. Пушкин: Еще не перестали топать,/ Сморкаться, кашлять, шикать, хлопать;/ Еще снаружи и внутри/ Везде блистают фонари;/ Еще, прозябнув, бьются кони,/ Наскуча упряжью своей,/ И кучера, вокруг огней,/ Бранят господ и бьют в ладони [10. С. 14] (здесь и далее курсив мой. - H.T.).

E. Lo Gatto (прозаический перевод): Gli spettatori non hanno cessato di battere i piedi, di soffiarsi, di tossire, di zittire e applaudire; ancora e di fuori e di dentro dappertutto scintillano i fanali; ancora, gelando, s’agitano i cavalli annoiati dei loro Finimenti, e i cochieri intorno ai fuochi sparlano dei padroni e battono le palme delle mani [12. P. 389-390].

Подстрочный перевод: Зрители не перестали топать, сморкаться, кашлять, шикать и хлопать; еще и снаружи, и внутри, везде сверкают фонари; еще, замерзнув, беспокоятся кони, уставшие от своей сбруи, и кучера вокруг огней злословят о хозяевах и бьют в ладони.

E. Lo Gatto (стихотворный перевод): non finiscono ancora di tossire,/ d'applaudir, di fischiare e di zittire;/ ancora sulla piazza e nei locali/ del teatro scintillano i fanali;/ ancor tremando sotto i finimenti/ s'agitano i cavalli e, indispettiti/per l'attesa i cocchieri intirizziti/ ai loro padroni mandano accidenti [9. P. 31].

Подстрочный перевод: Не перестали еще кашлять, хлопать, свистеть и шикать; еще на площади и в помещениях театра сверкают фонари; еще, дрожа под упряжью, беспокоятся кони и, рассерженные ожиданием, оцепеневшие (окоченевшие) кучера шлют своим хозяевам проклятия.

Мотив-образ театра является одним из повторяющихся сюжетно-композиционных узлов и каждый раз строится на комплексе более мелких, тоже повторяющихся мотивов-автореминисценций, закрепленных в следующих опорных понятиях: пространственная характеристика театра, визуальная характеристика, вариативный тип эмоционального поведения человека в театре ${ }^{11}$. «Прием повтора оказывается функционален в двух отношениях: автореминисцентные мотивы не только уподобляют каждый следующий вариант образа театра предыдущему, но и вызывают соответствующие ассоциации в том случае, если опорное слово-мотив возникает в тексте романа за пределами театрального эпизода <..> жизнь за стенами театра в “Евгении Онегине” имеет театральный внешний облик. Театральное действо как бы выплескивается из театрального здания и оформляет совершенно по сути отличное от театра пространство быта внешним подобием облика, позы, жеста, которое закреплено в тех же опорных словах» [13. С. 67]. В приведенном выше фрагменте оригинального текста можно наблюдать, как внешняя форма бытования театра (вариативный тип эмоционального поведения человека в театре) переходит в быт за его пределами: повтор, внешне уподобляющий жесты греющих руки кучеров аплодисментам зрителей (хлопать / бьют в ладони). В прозаическом переводе Ло Гатто данный повтор сохраняется (applaudire / battono le palme delle mani). Но в поэтическом переводе жест меняется: кучера не «аплодируют», они, напротив, застывают неподвижно, «цепенеют» («intirizziti» - «оцепеневшие, застывшие, окоченевшие»). Как интерпретировать данное переводческое решение, почему Ло Гатто изменяет жест кучеров? Невозможно отнести его на счет невнимательности или непонимания пушкинского текста, поскольку в прозаическом переводе Ло Гатто, хронологически предшествующему поэтическому, сохраняется оригинальный вариант поведения кучеров. Самым очевидным представляется, что выбор лексического эквивалента вызван рифмой «indispettiti intirizziti». В оригинальном тексте кучера «бьют в ладони», чтобы согреться, определение «оцепеневшие», «окоченевшие» также дает представление о том, что им холодно, следовательно, смысловое наполнение жеста сохраняется, утрачивается опорное слово-повтор, уподоблявший кучеров зрителям. Но появляется другой повтор: теперь оцепеневшие (intirizziti) кучера уподоблены не зрителям, а актерам, которых зрители ошикали (zittire). Конкретное опорное слово «хлопать», используемое в данном фрагменте у Пушкина, не повторяется у Ло Гатто, но повтор, придающий жизни за стенами театра театральный внешний облик, остается, переходя со словесно-образного уровня на звукобуквенный (zittire intirizziti). Не представляется возможным установить степень осознанности данного приема переводчиком, но вне зависимости от этого, стихотворный текст перевода оказывается способен репродуцировать имплицитные смыслы оригинала.

2. А.С. Пушкин: И вот уже трещат морозы/ И серебрятся средь полей.../ (Читатель ждет уж рифмы розы;; На, вот возьми ее скорей!) [10. С. 90].

E. Lo Gatto (прозаический перевод): Ed ecco il gelo scricchiola e inargentate luccicano nei campi... (il lettore s’aspetta già la rima rose ma sì, eccola, prendetevela!) [12. Р. 90].

Подстрочный перевод: И вот, мороз трещит и в полях блестят посеребренные... (читатель ждет уже рифмы «розы», ну да, вот она, возьмите ее!).

E. Lo Gatto (стихотворный перевод): Sotto i passi già crepitan, dal gelo/ inargentati i viottoli ed è grigio.../ (se t'aspetti, o lettor, la rima il cielo,/ mettila pur, mi renderai servigio) [9. Р. 110].

Подстрочный перевод: Под ногами уже скрипят морозом посеребренные тропы и серое (если ты ждешь, о, читатель, рифмы «небо», подставь же ее, мне окажешь услугу). 
В прозаическом переводе Ло Гатто остается в пределах пушкинского словесно-образного уровня («морозы-розы»), при этом теряется смысл пушкинской игры с читательскими ожиданиями и ассоциациями. В поэтическом переводе Ло Гатто находит образнолексический эквивалент: итальянский «мороз» - «il gelo» образует рифму с итальянским «небом» - «il cielo», образ «серого (мрачного, хмурого) неба» является возвышенным поэтическим образом, литературным штампом, который «снижается» посредством его «разоблачения». Кроме того, перевод выдержан в высоком стиле, на это указывает инверсия (стандартный порядок слов в итальянском языке был бы следующим: «crepitano i viottoli inargentati dal gelo» или «i viottoli inargentati dal gelo crepitano»), а также редукция окончаний в словах «сrepitano», «lettore», «pure». Ло Гатто удается воспроизвести пушкинский механизм обнажения «поэтической условности», и таким образом переводной текст активизирует те же самые ассоциативные способности у итальянского читателя, что и оригинал у читателя русского; лексическая отдаленность перевода Ло Гатто от оригинала оборачивается близостью стилистической и образной.

Резюмируя изложенные наблюдения, можно сделать следующие выводы: во-первых, появление вто- рого, стихотворного перевода Э. Ло Гатто обнаруживает его стремление преодолеть воздействие национальной переводческой традиции и максимально приблизиться к оригиналу, создать эквивалентный перевод, однако, прозаический комментарий внутри стихотворного текста демонстрирует, что, несмотря на то, что Ло Гатто преодолел в себе «изначальное неприятие стихотворного перевода» созданием собственного такого перевода, он не смог побороть ощущение коммуникативной и информативной недостаточности стихотворного текста. В то же время сам стихотворный текст перевода свидетельствует об обратном: возможности его ассоциативного и смыслопорождающего потенциала превышают возможности прозаического текста Ло Гатто; во-вторых, фрагменты из ранних и черновых редакций (в прозаическом переводе), от которых Пушкин в полной редакции отказался, и включение переводческого комментария непосредственно в текст (в стихотворном переводе) дают основания для постановки проблемы восприятия границ дефинитивного художественного текста в сознании переводчика и проблемы оригинальной жанровой природы переводов Э. Ло Гатто (синтез вольного, эквивалентного и филологического переводов)

\section{ПРИМЕЧАНИЯ}

1 L. Delatre. «Eugenio Anieghin» (1856), A. Besobrasoff, «Eugenio Oneghin» (1858), G. Cassone, «Eugenio Anieghin» (1906), E. Lo Gatto, «Eugenio Onjéghin» (1923), E. Lo Gatto, «Eugenio Oneghin» (1937), E. Bazzarelli, «Eugenio Onieghin» (1960), G. De Dominicis Jorio, «Evgenij Onegin» (1973), G. Giudici, «Eugenio Onieghin» (1975), P. Pera, «Evgenij Onegin» (1996), F. Gabbrielli, «Eugenio Onegin» (2006).

2 Подробно о Ло Гатто-русисте см.: [1. С. 9-32]. Библиографический список основных работ Э. Ло Гатто см.: [1. С. 150-154].

${ }^{3}$ Итал.: «la conoscenza della traduzione del Cassone in endecasillabi sciolti mi aveva confermato nell'opinione <...> della difficoltà o addirittura impossibilità di rendere in versi italiani la poesia straniera e in particolare di poeti come Puškin».

${ }^{4}$ Итал.: «la lettura e rilettura del «romanzo in versi» mi spinse a tradir me stesso. Considerando che il poeta russo in fondo aveva egli stesso in un certo senso negato che il suo «romanzo» potesse essere tradotto in prosa < ..> e in ciò consisteva la ragione della sua dichiarazione: «un romanzo in versi, una differenza diabolica», la mia decisione fu come una sfida a me stesso».

${ }^{5}$ Итал.: «Per l'adozione dell'endecasillabo fui guidato più dall’istinto che dal ragionamento».

${ }^{6}$ О соответствии между итальянскими и русскими размерами подробно см.: [6. Р. 107-127].

${ }^{7}$ Стихотворные варианты ответов Пушкина на предложения современников продолжить роман («Ты мне советуешь, Плетнев любезный...» и др.).

${ }^{8}$ Итал.: «"prisjadka” indica nella danza nazionale russa un insieme di movimenti che comprende il piegarsi sul ginocchi, il gettar rapidamente le gambe avanti e il risaltar su svelti».

${ }^{9}$ Итал.: «Siamo soliti dire il Volga. Sarebbe necessario lasciare il nome al femminile, riflettendo al significato che ha per i russi "la madre Volga» (Прим.: il - артикль мужского рода, la - женского. - H.T.).

10 Черновые варианты к примечанию 5.

${ }^{11}$ Об этом подробно см.: [13. С. 66-75].

\section{ЛИТЕРАТУРА}

1. Ло Гатто Э. Мои встречи с Россией / пер. К. Гладыш, И. Дергачевой. М. : Кругъ, 1992. 160 с.: ил.

2. Lo Gatto E. Criteri di traduzione in versi dell'Evgenij Onegin // La traduzione letteraria dal russo nelle lingue romanze e dalle lingue romanze in russo. Milano, 1979. P. 208-216.

3. Шишкин А.Б., Сульпассо Б. Переписка Вячеслава Иванова и Этторе Ло Гатто: Вячеслав Иванов: исследования и материалы. СПб. : Издво Пушкинского Дома, 2010. Вып. 1. С. 759-779.

4. Гачечиладзе Г. Стихосложение и поэтический перевод (фрагмент) // Поэтика перевода : сб. ст. М. : Радуга, 1988. С. 88-99.

5. Иванов Вяч. О языковых причинах трудностей перевода художественного текста // Поэтика перевода : сб. ст. М. : Радуга, 1988. С. 69-87.

6. Colucci M. Del tradurre poeti russi (e non solo russi) // Europa orientalis. 1993. № 7. Р. 107-127.

7. Иванов Вяч. Лик и личины России: эстетика и литературная теория. М. : Искусство, 1995. 669 с.

8. Puškin A. Eugenio Onjeghin: traduzione, introduzione e note di Ettore Lo Gatto. Firenze : G.C. Sansoni, 1925. 271 p.

9. Puškin A. Eugenio Oneghin: romanzo in versi. (Trad. in versi di E. Lo Gatto; introd. di V. Ivanov). Firenze : Sansoni, 1967. 285 p.

10. Пушкин А.С. Полное собрание сочинений : в 19 т. / ред. Б.В. Томашевский. М. : Воскресенье, 1999. Т. 6. 697, [3] с.: 1 л. порт.

11. Гончаренко С. Стиховые структуры лирического текста и поэтический перевод // Поэтика перевода : сб. ст. М. : Радуга, 1988.235 с.

12. Puškin A. Opere poetiche: a cura di Ettore Lo Gatto. Milano : Mursia, 1985. 885 p.

13. Лебедева О.Б. «Мотив театра в сюжетосложении романа А.С. Пушкина «Евгений Онегин» // Мотивы и сюжеты русской литературы. От Жуковского до Чехова: К 50-летию научно-педагогической деятельности Ф.З. Кануновой : сб. ст. / отв. ред. А.С. Янушкевич. Томск : Знамя Мира, 1997. С. 66-75. 


\section{Alexander Pushkin's Novel Eugene Onegin in Translations by Ettore Lo Gatto}

Vestnik Tomskogo gosudarstvennogo universiteta - Tomsk State University Journal, 2019, 441, 62-67. DOI: $10.17223 / 15617793 / 441 / 8$

Natalia A. Tik, Tomsk State University (Tomsk, Russian Federation). E-mail: tiknataly@yandex.ru

Keywords: Ettore Lo Gatto; Eugene Onegin; literary translation; Pushkin studies; Russian-European literature connections.

This research investigates the translations of Alexander Pushkin's novel Eugene Onegin by the Italian Slavist Ettore Lo Gatto. He translated the novel into prose in 1923, but 14 years later he offered Italian readers a new poetic version of the masterpiece, which was in hendecasyllable (traditional Italian meter). The author considers the problem of selecting the form for the translations in the context of the Italian tradition of translation (prosaic translation of poetry); the dynamics of Lo Gatto's translation strategy: "I wanted to defeat my own aversion to poetic translation in general, to defeat it with my own poetic translation"; the transformation of the original's composition; the potential of Lo Gatto's prosaic and poetic translation for conveying the richness of meaning in Pushkin's text (analysis of such elements of the novel's text as thematic iteration and a game with the reader). Eugene Onegin was published twice (1833, 1837) during Pushkin's life in the versions that were exactly as written by the poet himself. This indicates that the text is definitive. However, in both translations by Lo Gatto, at the level of composition, we can observe a number of discrepancies with Pushkin's definitive wording. In the prosaic translation, Lo Gatto swaps parts of the composition and includes fragments from the early and draft editions of the novel. In the poetic translation, the deviation from the definitive text is the inclusion of the translator's commentary directly into the text, so that there is a merging of the translation and the commentary. Lo Gatto's recourse to the previous editions and drafts of the novel, their introduction to the translations, and his desire to comment on the text show the intention of the translator to convey the meaning of Pushkin's novel to the Italian reader, an audience that was totally unfamiliar with it, accurately and as fully as possible. But his recourse to this material also demonstrates the problem of the translator's perception of the boundaries of the definitive literary text. The second, poetic translation by Lo Gatto reveals his desire to overcome the impact of the national tradition of translation and come as close as possible to the original, to create an equivalent translation. However, the prosaic translation commentary inside the poetic text demonstrates that although Lo Gatto overcame his "own aversion to poetic translation in general" by creating his own poetic translation, he could not overcome the feeling of the communicative and informative insufficiency of the poetic text. At the same time, the poetic translation of the novel testifies to the opposite: its richness exceeds that of Lo Gatto's prosaic translation.

\section{REFERENCES}

1. Lo Gatto, E. (1992) Moi vstrechi s Rossiey [My meetings with Russia]. Translated from Italian by K. Gladysh, I. Dergacheva. Moscow: Krug”.

2. Lo Gatto, E. (1979) Criteri di traduzione in versi dell’Evgenij Onegin. In: La traduzione letteraria dal russo nelle lingue romanze e dalle lingue romanze in russo. Milano: Cisalpino-Goliardica.

3. Shishkin, A.B. \& Sul'passo, B. (2010) Perepiska Vyacheslava Ivanova i Ettore Lo Gatto: Vyacheslav Ivanov: issledovaniya i materialy [Correspondence of Vyacheslav Ivanov and Ettore Lo Gatto: Vyacheslav Ivanov: studies and materials]. Is. 1. St. Petersburg: Izd-vo Pushkinskogo Doma. pp. 759-779.

4. Gachechiladze, G. (1988) Stikhoslozhenie i poeticheskiy perevod (fragment) [Versification and poetic translation (fragment)]. In: Goncharenko, S. (ed.) Poetika perevoda [Poetics of translation]. Moscow: Raduga.

5. Ivanov, V. (1988) O yazykovykh prichinakh trudnostey perevoda khudozhestvennogo teksta [On the linguistic reasons for the difficulties of translating a literary text]. In: Goncharenko, S. (ed.) Poetika perevoda [Poetics of translation]. Moscow: Raduga.

6. Colucci, M. (1993) Del tradurre poeti russi (e non solo russi). Europa orientalis. 7. pp. 107-127.

7. Ivanov, V. (1995) Lik i lichiny Rossii: estetika i literaturnaya teoriya [The face and masks of Russia: aesthetics and literary theory]. Moscow: Iskusstvo.

8. Puškin, A. (1925) Eugenio Onjeghin: traduzione, introduzione e note di Ettore Lo Gatto. Firenze: G.C. Sansoni.

9. Puškin, A. (1967) Eugenio Oneghin: romanzo in versi. (Trad. in versi di E. Lo Gatto; introd. di V. Ivanov). Firenze: Sansoni.

10. Pushkin, A.S. (1999) Polnoe sobranie sochineniy: $v 19$ t. [Complete Works: in 19 vols]. Vol. 6. Moscow: Voskresen’e.

11. Goncharenko, S. (1988) Stikhovye struktury liricheskogo teksta i poeticheskiy perevod [Verse structures of a lyrical text and poetic translation]. In: Goncharenko, S. (ed.) Poetika perevoda [Poetics of translation]. Moscow: Raduga.

12. Puškin ,A. (1985) Opere poetiche: a cura di Ettore Lo Gatto. Milano: Mursia.

13. Lebedeva, O.B. (1997) Motiv teatra v syuzhetoslozhenii romana A.S. Pushkina "Evgeniy Onegin” [The motive of the theater in the plot of A.S. Pushkin’s novel “Eugene Onegin”]. In: Yanushkevich, A.S. (ed.) Motivy i syuzhety russkoy literatury. Ot Zhukovskogo do Chekhova: K 50-letiyu nauchno-pedagogicheskoy deyatel'nosti F.Z. Kanunovoy [Motives and plots of Russian literature. From Zhukovsky to Chekhov: To the 50th anniversary of the scientific and educational activities of F.Z. Kanunova]. Tomsk: Znamya Mira. 